Chromosoma (Berl.) 40, 269—284 (1973)

(C) by Springer-Verlag 1973

\title{
Discrimination between Groups of Chromosomes and Individual Chromosomes in the Normal Human Karyotype
}

\author{
James E. Harris, Carlos E. Nasjleti, and Charles J. Kowalski \\ Department of Orthodontics, Veterans Administration Hospital \\ and Statistical Research Laboratory, University of Michigan, Ann Arbor, \\ Michigan
}

Abstract. The karyotypes of 200 normal individuals are examined in a study designed to investigate the extent to which the cytologist's classification of chromosomes into the A-G autosomal groups and identification of individual chromosomes are reflected in the values of measurements made on these chromosomes. The statistical technique of discriminant function analysis is employed to obtain linear functions of the chromosomal measurements which may be used to classify and identify chromosomes. The results of the study indicate that while chromosomes can be grouped with a reasonably high probability of success using measurements alone, identification of individual chromosomes is somewhat more difficult.

\section{Introduction}

Since the appearance of the Denver Report (1960), there has been considerable interest in questions relating to the accuracy with which individual human chromosomes can be identified by morphological means alone (Sharat Chandra and Hungerford, 1967). At least two papers have appeared (Tjio and Puck, 1958; Chu and Giles, 1959) in which it is claimed that individual chromosomes can be identified solely on the basis of the measured lengths of the arms, but this claim has not been universally accepted. In particular, Patau (1962) has challenged this assertion, suggesting instead that, "... many of the idiograms with which the cytologic literature abounds are probably worthless". While he did concede that groups of chromosomes may be distinguishable, Patau (1962) minimized the usefulness of measurements in this regard stating, "... the human eye can often draw valid distinctions between chromosomes that do not differ enough in the true lengths of their arms to make possible their reliable distinction by length measurements alone". An intermediate view was advanced by Moore and Gregory (1963).

In this paper we employ the statistical technique of discriminant function analysis to investigate the extent to which normal human chromosomes can be allocated to the proper A-G chromosomal groups

19 Chromosoma (Berl.), Bd. 40 
on the basis of measurements made on these chromosomes and, further, the extent to which the individual chromosomes within these subgroups can be identified. The identification of the sex chromosomes is also considered. Otherwise stated, we consider the question: From measurements alone, how accurately may a chromosome be characterized and identified as compared with the experienced eye of the cytologist in preparing a karyotype? The technique of discriminant function analysis was introduced by Fisher (1936). Two useful and detailed summaries of various applications of discriminant analysis were given by Hodges (1950) and Tatswoka and Tiedeman (1954); both of these papers include extensive bibliographies. Medical applications were surveyed by Radhakrishna (1964). The appropriate situation for the application of a discriminant function analysis is one in which there are several groups of items, several measurements having been made upon each item. A new item is presented and it is required to construct optimally weighted combinations of the measurements (the discriminant functions), by means of which the new item can be allocated to its group. The weights are determined to minimize the probabilities of misclassification or, equivalently, to maximally separate the groups with respect to the distributions of these compound measurements. Thus, in our application, the weights of the chromosomal measurements are determined to maximally separate the chromosomal groups under consideration. A rigorous mathematical treatment may be found in Anderson (1958); a more heuristic approach to the derivation of the method is available in Healey (1965).

\section{Methods and Materials}

Because of the controversy among many cytologists concerning the reliability and reproducibility of the human karyotype (Ford, 1961), and because of the fact that the accuracy of the discriminant function approach to the elassification of chromosomes will be directly determined by the original classifications made by the cytologist (c.f. Lachenbruch, 1966), the karyotypes of the 200 individuals (100 males and 100 females) which comprise the basic data for our study were prepared and measured entirely by a single investigator (C.E.N.). These individuals were normal, healthy people between 20 and 40 years of age; most of them were employed at the Veterans Administration Hospital in Ann Arbor, Michigan. Metaphase figures were obtained from the leucocyte component of the peripheral blood, essentially following the technique of Moorhead et al. (1960). The slight modifications introduced by us to this method, as well as the step-by-step sequence used for chromosomal spreading and staining, and the photographic procedures employed, have been documented elsewhere (Nasjleti et al., 1966). After photography, cell metaphases were selected for readability, absence of chromosomal overlapping and comparability with respect to the attained stage of colcemide-mitosis. Later each of the chosen metaphase figures was photographically enlarged and printed on single weight $25 \times 30$ centimeter paper, with a standard magnification of 8000 diameters. Individual chromosomes were cut out from each print and mounted on a card, in order of decreasing size, 
into pairs of presumed homologous chromosomes. This order was occasionally modified by factors other than size, e.g., arm ratios and/or centromere position, the degree of contraction of the chromatids, the degree of staining, the presence of secondary constrictions, the presence (absence) of satellites and spatial position in the metaphase figures (ef. Miller et al., 1963; Sharat Chandra and Hungerford, 1967), but the final sequence of homologous pairs were numbered and grouped in accordance with the scheme recommended by the Chicago Conference (1966). These karyotypes, arrayed on cards and each filed with an uncut print of the cell metaphase, formed the basic material used in the present study.

The chromosomes were measured with a mechanical divider and these measurements were found to be accurate to $0.05 \mathrm{~mm}$ when every fifth karyotype was remeasured. Again, it is important to emphasize that all the chromosomes were prepared, measured and recorded by the same investigator. The following measurements were recorded (cf. Fig. 1): the length of the short arm $\left(M_{1}\right)$, the length of the long arm $\left(M_{2}\right)$, the total length of the chromosome $\left(M_{3}=M_{1}+M_{2}\right)$, the ratio of the short arm to the long arm $\left(M_{4}=M_{1} / M_{2}\right)$, the centromere index $\left(M_{5}=M_{1} / M_{3}\right)$ and the relative chromosome length $\left(M_{6}\right)$ which represents the individual chromosome as a percentage of the sum of the lengths of the entire chromosome complement, excluding the sex chromosomes. The average of the homologous chromosome measurements was used for each pair. In actuality, of course, the total length, arm ratio, centromere index and relative length measurements are functions of the lengths of the short and long arms and these measurements were in fact computed from the values of $M_{1}$ and $M_{2}$ using a program written expressly for this purpose. The ratio $M_{1} / M_{2}$ was used in place of the more traditional chromosomal measurement $M_{2} / M_{1}$ in order to reduce the range of variation of this measurement.

The first question we consider is whether the assignment to groups made by the cytologist is reflected in the values of these measurements, i.e., can the measurements be used to classify individual chromosomes into the proper chromosomal groups. While not all of the measurements defined above are independent, e.g., $M_{3}=M_{1}+M_{2}$, they were all recorded since our intent is to find the optimal set of discriminators and to study the discriminatory power of various subsets of the measurements actually recorded. In particular, it is of interest to study whether or not any single measurement can effectively discriminate between the groups. For example, a glance at Fig. 2, which contains plots of the mean values of the long and short chromosome arm measurements for the 200 karyotypes, clearly illustrates the fact that the mean values of these measurements are considerably different in the $A-G$ autosomal groups. But, while the mean values of these measurements are quite different in the chromosomal groups considered, we need to apply discriminant function analysis in order to see whether or not these measurements are sufficiently characteristic of the groups for use in classification (cf. Kowalski, 1972). The discriminant function analyses were performed by the statistical computing program BMD7M (Dixon, 1967) as modified by the Statistical Research Laboratory at the University of Michigan. This program performs a multiple discriminant function analysis in a stepwise manner. At each step one measurement is entered into or removed from 


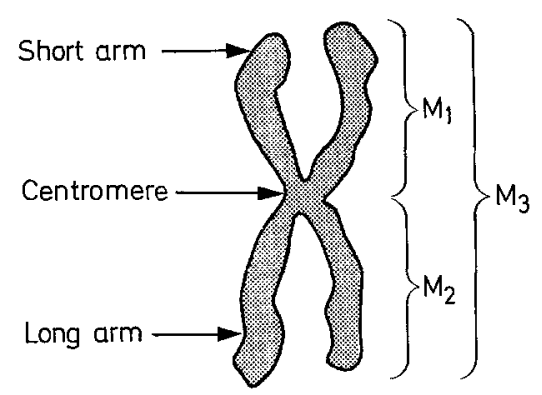

Fig. 1. Illustration of several of the chromosomal measurements employed in our attempt to characterize chromosomal morphology

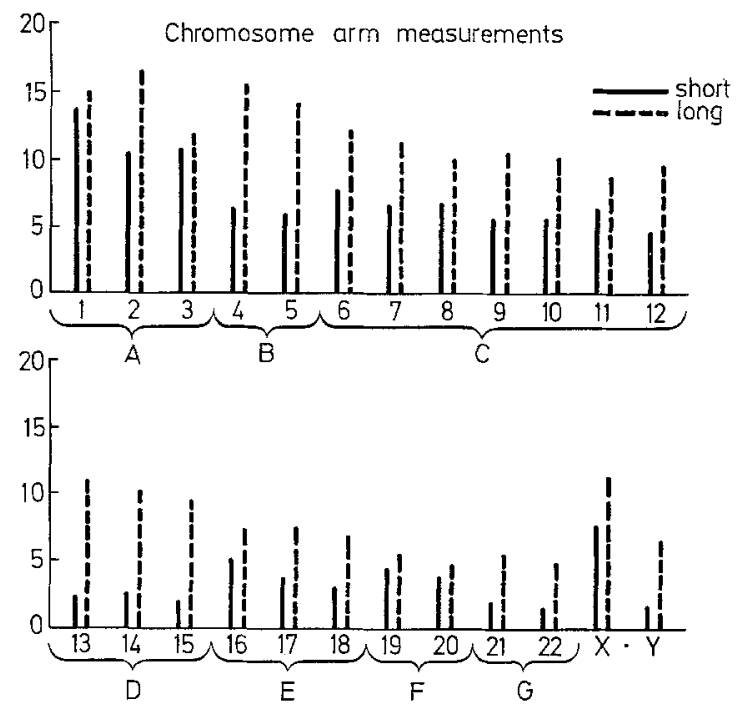

Fig. 2. Plot of the mean values of the chromosome arm measurements based on the karyotypes of 200 normal individuals

the set of discriminating measurements. If a measurement is to be entered, the measurement selected is that measurement with the largest F-value (under the usual normality assumptions, the $F$-value for the $i$-th measurement is the value of the test statistic for the likelihood ratio test of the equality, over all groups, of the conditional distribution of the $i$-th measurement given the previously entered measurements). A measurement will be removed if, during later stages of the process, its $F$-value becomes too low. The process terminates when none of the $F$-values for either adding or deleting a measurement attains a pre- 
specified level of significance. Of course, if only one measurement is considered, as in Tables 1-4 below, the stepwise option of the program is "turned off" and the rule which minimizes the probabilities of misclassification using this one measurement is adopted.

\section{Results}

Tables 1 through 4 give the classification matrices for discriminant analyses using only a single measurement at a time in order of decreasing

Table 1. Classification matrix for the discriminant analysis based on the relative length $\left(M_{6}\right)$ of the chromosomes. A total of 1143 of the 4400 chromosomes were misclassified

\begin{tabular}{|c|c|c|c|c|c|c|c|c|}
\hline Groups & $\begin{array}{l}A \\
1-3\end{array}$ & $\begin{array}{l}\mathrm{B} \\
4-5\end{array}$ & $\begin{array}{l}\mathrm{C} \\
6-12\end{array}$ & $\begin{array}{l}\mathrm{D} \\
13-15\end{array}$ & $\begin{array}{l}\mathrm{E} \\
16-18\end{array}$ & $\begin{array}{l}\mathrm{F} \\
19-20\end{array}$ & $\begin{array}{l}\mathrm{G} \\
21-22\end{array}$ & $\begin{array}{l}\text { Mis- } \\
\text { classified }\end{array}$ \\
\hline A & 455 & 153 & 2 & 0 & 0 & 0 & 0 & 155 \\
\hline B & 10 & 378 & 12 & 0 & 0 & 0 & 0 & 22 \\
\hline $\mathrm{C}$ & 0 & 185 & 1114 & 101 & 0 & 0 & 0 & 286 \\
\hline $\mathrm{D}$ & 0 & 1 & 18 & 406 & 159 & 16 & 0 & 194 \\
\hline $\mathrm{E}$ & 0 & 0 & 5 & 164 & 282 & 149 & 0 & 318 \\
\hline F & 0 & 0 & 0 & 6 & 75 & 269 & 50 & 131 \\
\hline \multirow[t]{2}{*}{ G } & 0 & 1 & 0 & 0 & 0 & 36 & 363 & 37 \\
\hline & & & & & & & Total & 1143 \\
\hline
\end{tabular}

efficiency in grouping the chromosomes into the proper $A-G$ groups. Thus Table 1 summarizes the efficacy of the relative length $\left(M_{6}\right)$ of the chromosome in classification. The numbers on the diagonal of this matrix show the numbers of chromosomes correctly classified into the indicated groups; the numbers off the diagonal represent misclassifications. Thus, for example, 445 of the chromosomes classified as belonging to the A group by the cytologist were also (correctly) classified as from the A group by the discriminant funetion analysis, but 153 of these chromosomes were (incorrectly) classified by the discriminant analysis as from the $\mathrm{B}$ group. In total, although relative length is the best single discriminator among the measurements considered, there were 1143 of the 4400 chromosomes misclassified $(26 \%)$. One might note, however, that most of the misclassifications were to adjacent groups and that the procedure works quite well within several of the groups considered. Tables 2-4 contain the analogous results for total length, arm ratio and centromeric index respectively. The short and long arm measurements, despite the apparent differences in the mean values of these measure- 
Table 2. Classification matrix for the discrimination analysis based on the total length $\left(M_{3}\right)$ of the chromosomes. A total of 2118 of the 4400 chromosomes were misclassified

\begin{tabular}{|c|c|c|c|c|c|c|c|c|}
\hline Group & $\begin{array}{l}\text { A } \\
1-3\end{array}$ & $\begin{array}{l}\text { B } \\
45\end{array}$ & $\begin{array}{l}\mathrm{C} \\
6-12\end{array}$ & $\begin{array}{l}\mathrm{D} \\
13-15\end{array}$ & $\begin{array}{l}\mathrm{E} \\
16-18\end{array}$ & $\begin{array}{l}\mathrm{F} \\
19-20\end{array}$ & $\begin{array}{l}\mathrm{G} \\
21-22\end{array}$ & $\begin{array}{l}\text { Mis- } \\
\text { classified }\end{array}$ \\
\hline A & 931 & 167 & 51 & 1 & 0 & 0 & 0 & 209 \\
\hline B & 97 & 190 & 104 & 9 & 0 & 0 & 0 & 210 \\
\hline C & 44 & 274 & 722 & 289 & 63 & 8 & 0 & 678 \\
\hline D & 0 & 0 & 111 & 239 & 142 & 95 & 13 & 361 \\
\hline $\mathrm{E}$ & 1 & 0 & 34 & 176 & 190 & 160 & 39 & 410 \\
\hline $\mathrm{F}$ & 0 & 0 & 0 & 21 & 76 & 212 & 91 & 188 \\
\hline \multirow[t]{2}{*}{$\mathrm{G}$} & 0 & 0 & 1 & 0 & 2 & 59 & 388 & 62 \\
\hline & & & & & & & \multicolumn{2}{|c|}{ Total 2118} \\
\hline
\end{tabular}

Table 3. Classification matrix for the discriminant analysis based on the arm ratio $\left(M_{4}\right)$ of the chromosomes. A total of 2568 of the 4400 chromosomes were misclassified

\begin{tabular}{|c|c|c|c|c|c|c|c|c|}
\hline Group & $\begin{array}{l}A \\
1-3\end{array}$ & $\begin{array}{l}\mathrm{B} \\
4-5\end{array}$ & $\begin{array}{l}\mathrm{C} \\
6-12\end{array}$ & $\begin{array}{l}\mathrm{D} \\
13-15\end{array}$ & $\begin{array}{l}E \\
16-18\end{array}$ & $\begin{array}{l}F \\
19-20\end{array}$ & $\begin{array}{l}\mathrm{G} \\
21-22\end{array}$ & $\begin{array}{l}\text { Mis- } \\
\text { classified }\end{array}$ \\
\hline A & 31 & 2 & 178 & 0 & 12 & 376 & 1 & 569 \\
\hline B & 0 & 314 & 1 & 0 & 29 & 0 & 56 & 86 \\
\hline C & 193 & 239 & 536 & 1 & 386 & 36 & 9 & 864 \\
\hline D & 1 & 2 & 0 & 507 & 0 & 1 & 89 & 93 \\
\hline $\mathrm{E}$ & 99 & 192 & 120 & 2 & 139 & 17 & 31 & 461 \\
\hline $\mathrm{F}$ & 192 & 1 & 30 & 0 & 1 & 176 & 0 & 224 \\
\hline \multirow[t]{2}{*}{$G$} & 1 & 107 & 7 & 127 & 29 & 0 & 129 & 271 \\
\hline & & & & & & & \multicolumn{2}{|c|}{ Total 2568} \\
\hline
\end{tabular}

ments in the A-G groups as illustrated in Fig. 2, showed even less discriminatory power than the other single measurements and are not studied in detail here.

In view of these results it appears that no one of the single measurements is a particularly effective discriminator, but using some combination of all of the available measurements may still result in an effective classification procedure. This possibility can be investigated by use of a stepwise discriminant function analysis. In Table 5, using all available measurements, the stepwise discriminant function analysis is able to correctly classify most of the chromosomes; a total of 288 of the 4400 chromosomes $(6.5 \%)$ were misclassified. The order of inclusion of the measurements into the discriminant functions was (1) relative length, (2) centromere index, (3) arm ratio, (4) short arm and (5) long arm. 
Table 4. Classification matrix for the discriminant analysis based on the centromeric index $\left(M_{4}\right)$ of the chromosomes. A total of 2574 of the 4400 chromosomes were misclassified.

\begin{tabular}{|c|c|c|c|c|c|c|c|c|}
\hline Group & $\begin{array}{l}\mathrm{A} \\
1-3\end{array}$ & $\begin{array}{l}\mathrm{B} \\
4-5\end{array}$ & $\begin{array}{l}\mathrm{C} \\
6-12\end{array}$ & $\begin{array}{l}\mathrm{D} \\
13-15\end{array}$ & $\begin{array}{l}E \\
16-18\end{array}$ & $\begin{array}{l}\mathrm{F} \\
19-20\end{array}$ & $\begin{array}{l}\mathrm{G} \\
21-22\end{array}$ & $\begin{array}{l}\text { Mis- } \\
\text { classified }\end{array}$ \\
\hline A & 34 & 2 & 173 & 0 & 7 & 384 & 0 & 566 \\
\hline B & 0 & 322 & 3 & 0 & 31 & 0 & 44 & 78 \\
\hline $\mathrm{C}$ & 248 & 224 & 505 & 1 & 367 & 49 & 6 & 895 \\
\hline $\mathrm{D}$ & 1 & 7 & 0 & 489 & 0 & 0 & 103 & 111 \\
\hline $\mathrm{E}$ & 109 & 187 & 122 & 2 & 134 & 24 & 22 & 466 \\
\hline $\mathrm{F}$ & 174 & 1 & 20 & 0 & 1 & 204 & 0 & 196 \\
\hline \multirow[t]{2}{*}{ G } & 1 & 109 & 7 & 114 & 31 & 0 & 138 & 262 \\
\hline & & & & & & & \multicolumn{2}{|c|}{ Total 2574} \\
\hline
\end{tabular}

Thus (cf. Table 1) the best single discriminator is the relative length of the chromosome. Given that relative length is to be included into the discriminant functions, the measurement with the most new discriminatory power is the centromere index. Next was the arm ratio, and so on. Note that this ordering of the measurements in terms of discriminatory power does not contradict the ordering given in Tables 1-4 where each

Table 5. Classification matrix for the stepwise discriminant function analysis based on all available measurements. Five variables were entered, each significant at the $1 \%$ level of significance. A total of 288 of the 4400 chromosomes were misclassified

\begin{tabular}{|c|c|c|c|c|c|c|c|c|}
\hline Group & $\begin{array}{l}\mathrm{A} \\
1-3\end{array}$ & $\begin{array}{l}\mathrm{B} \\
4-5\end{array}$ & $\begin{array}{l}\mathrm{C} \\
6-12\end{array}$ & $\begin{array}{l}\mathrm{D} \\
13-15\end{array}$ & $\begin{array}{l}\mathrm{E} \\
16-18\end{array}$ & $\begin{array}{l}\mathbf{F} \\
19-20\end{array}$ & $\begin{array}{l}\mathrm{G} \\
21-22\end{array}$ & $\begin{array}{l}\text { Mis- } \\
\text { classified }\end{array}$ \\
\hline A & 572 & 11 & 17 & 0 & 0 & 0 & 0 & 28 \\
\hline B & 0 & 387 & 13 & 0 & 0 & 0 & 0 & 13 \\
\hline C & 6 & 22 & 1336 & 2 & 27 & 7 & 0 & 64 \\
\hline D & 0 & 0 & 3 & 577 & 13 & 0 & 7 & 23 \\
\hline $\mathrm{E}$ & 0 & 1 & 11 & 1 & 500 & 63 & 24 & 100 \\
\hline $\mathrm{F}$ & 0 & 0 & 0 & 0 & 20 & 380 & 0 & 20 \\
\hline \multirow[t]{2}{*}{ G } & 0 & 0 & 1 & 1 & 35 & 3 & 360 & 40 \\
\hline & & & & & & & \multicolumn{2}{|c|}{ Total 288} \\
\hline
\end{tabular}

of the variables was considered individually. The order of inclusion of variables into the discriminant functions as determined by the stepwise discriminant function analysis (Table 5) is based on conditional distri- 


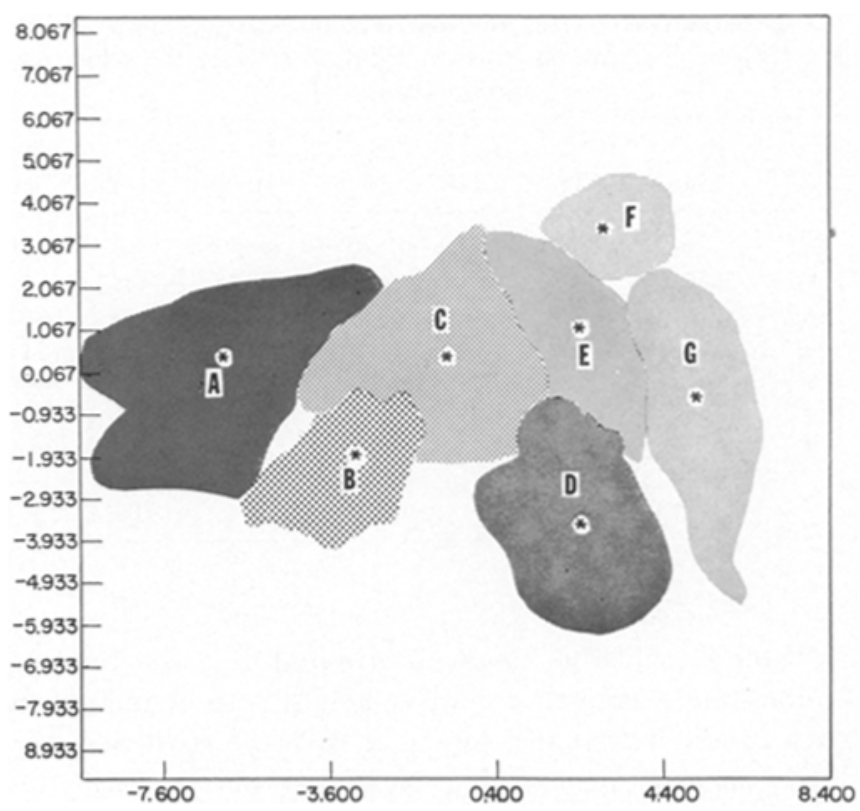

Fig. 3. Plot of the first two canonical variables for the autosomal groups, illustrating the separation between the groups which can be achieved using the values of five measurements. The *'s denote the group means

bution theory, selecting at each stage the measurement adding the most new (non-redundant) discriminatory power, taking due account of the correlations between the variables. In any event, all five measurements entered were significant at the $1 \%$ level of significance and total length $\left(M_{3}=M_{1}+M_{2}\right)$ was excluded since it is a linear combination of the lengths of the short and long arms.

The amount of separation between the groups that can be achieved by use of these measurements is illustrated in Fig. 3 where a plot of the values of the first and second canonical variables for the input observations is given. Not every individual point on the graph is shown but, rather, the areas occupied by the points from a particular group are identified. This plot gives the optimal two-dimensional representation of the dispersion between the groups (Dixon, 1967). For a careful discussion and a number of illustrations of this technique, see Blackith and Reyment (1971).

In Table 6, the classification matrix for the discriminant analysis based on all the available measurements between the A-G autosomal groups and the $\mathrm{X}$ chromosome is given. It is seen that considerable 


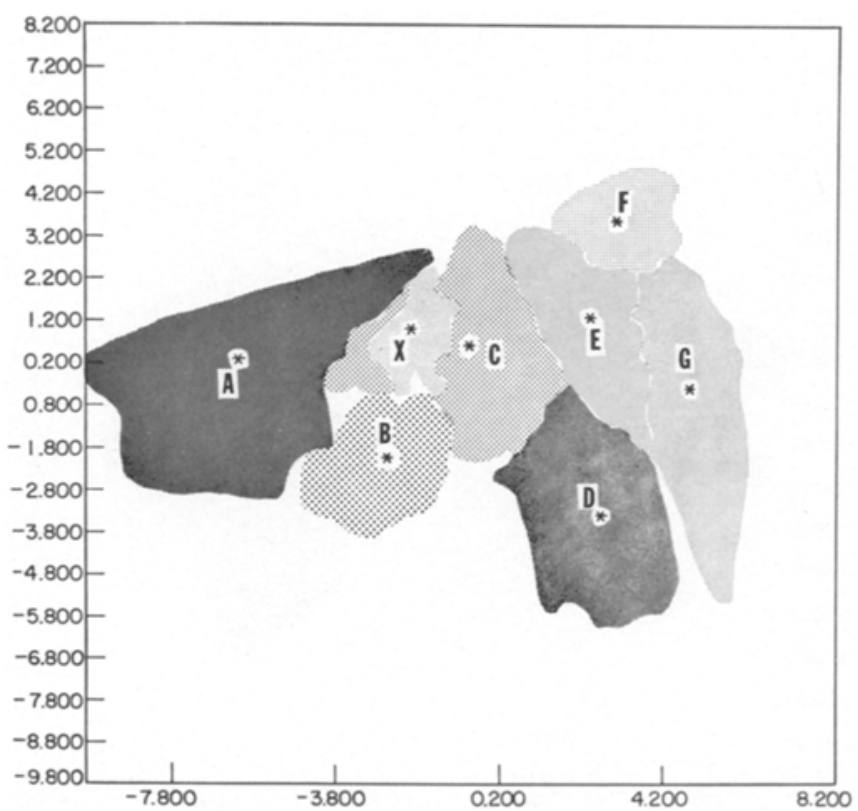

Fig. 4. Canonical plot when the $X$ chromosome is included in the analysis

Table 6. Classification matrix for the stepwise discriminant function analysis including the $\mathrm{X}$ ehromosomes

\begin{tabular}{|c|c|c|c|c|c|c|c|c|}
\hline Group & $\begin{array}{l}A \\
1-3\end{array}$ & $\begin{array}{l}\mathrm{B} \\
4-5\end{array}$ & $\begin{array}{l}\mathrm{C} \\
6-12\end{array}$ & $\begin{array}{l}\mathrm{D} \\
13-15\end{array}$ & $\begin{array}{l}\mathrm{E} \\
16-18\end{array}$ & $\begin{array}{l}F \\
19-20\end{array}$ & $\begin{array}{l}\mathrm{G} \\
21-22\end{array}$ & $X$ \\
\hline A & 528 & 8 & 1 & 0 & 0 & 0 & 0 & 63 \\
\hline B & 0 & 382 & 7 & 0 & 0 & 0 & 0 & 11 \\
\hline C & 1 & 12 & 1030 & 2 & 27 & 8 & 0 & 320 \\
\hline $\mathrm{D}$ & 0 & 0 & 4 & 576 & 13 & 0 & 7 & 0 \\
\hline $\mathrm{E}$ & 0 & 0 & 12 & 1 & 491 & 63 & 33 & 0 \\
\hline $\mathrm{F}$ & 0 & 0 & 0 & 0 & 20 & 380 & 0 & 0 \\
\hline G & 0 & 0 & 0 & 5 & 36 & 3 & 355 & 1 \\
\hline$X$ & 0 & 1 & 6 & 1 & 1 & 0 & 0 & 191 \\
\hline
\end{tabular}

misclassification occurs between the $\mathrm{C}$ group and the $\mathrm{X}$ chromosome. Thus the data reported here tend to support the oft-cited morphological similarity between the $\mathrm{X}$ chromosome and the chromosomes comprising the $\mathrm{C}$ group. This is illustrated by the position of the $\mathrm{X}$ chromosome in the plot of the canonical variables given in Fig. 4. The spatial position of the $\mathrm{X}$ chromosome in Fig. 4 is mirrored in the pattern of misclassifica- 


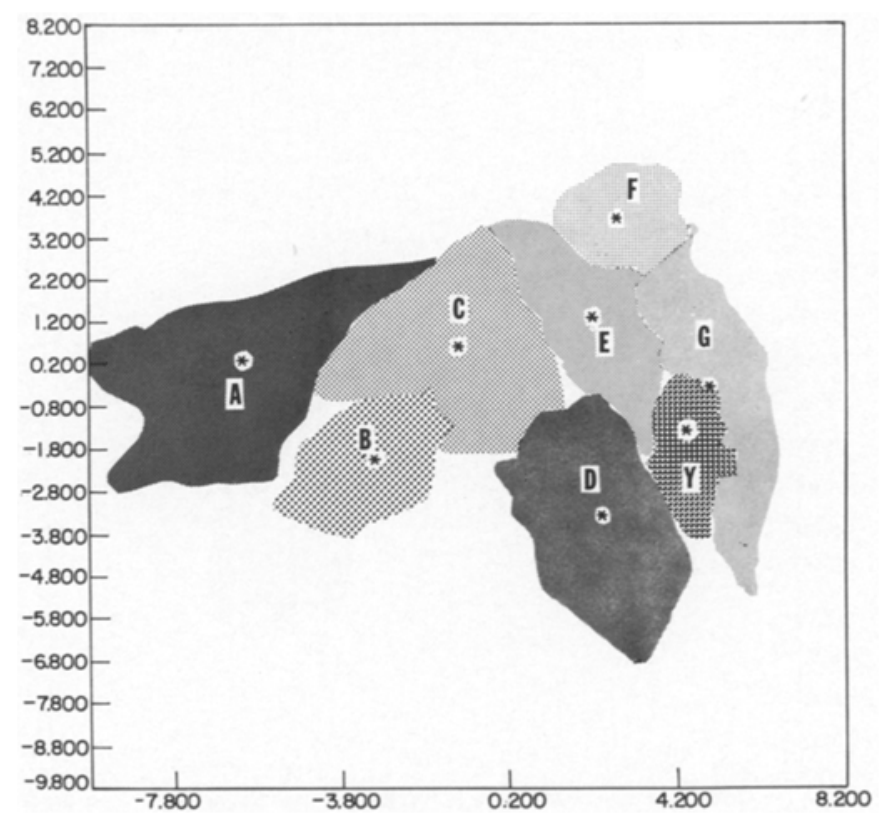

Fig. 5. Canonical plot when the $\mathrm{Y}$ chromosome is included in the analysis

Table 7. Classification matrix for the stepwise discriminant function analysis including the $\mathrm{Y}$ ehromosomes

\begin{tabular}{|c|c|c|c|c|c|c|c|c|}
\hline Group & $\begin{array}{l}A \\
1-3\end{array}$ & $\begin{array}{l}B \\
4-5\end{array}$ & $\begin{array}{l}\mathrm{C} \\
6-12\end{array}$ & $\begin{array}{l}\mathrm{D} \\
13-15\end{array}$ & $\begin{array}{l}E \\
16-18\end{array}$ & $\begin{array}{l}F \\
19-20\end{array}$ & $\begin{array}{l}G \\
21-22\end{array}$ & $Y$ \\
\hline A & 571 & 12 & 17 & 0 & 0 & 0 & 0 & 0 \\
\hline B & 0 & 387 & 13 & 0 & 0 & 0 & 0 & 0 \\
\hline C & 7 & 20 & 1337 & 2 & 26 & 8 & 0 & 0 \\
\hline D & 0 & 0 & 3 & 552 & 12 & 0 & 0 & 33 \\
\hline $\mathrm{E}$ & 0 & 1 & 10 & 1 & 496 & 63 & 11 & 18 \\
\hline $\mathrm{F}$ & 0 & 0 & 0 & 0 & 21 & 379 & 0 & 0 \\
\hline $\mathrm{G}$ & 0 & 0 & 1 & 0 & 36 & 3 & 262 & 98 \\
\hline $\mathrm{Y}$ & 1 & 1 & 0 & 0 & 1 & 0 & 29 & 67 \\
\hline
\end{tabular}

tions in Table 6 , illustrating the way in which the classification matrix and the canonical plot conveniently summarize the results of a discriminant function analysis.

In Table 7 and Fig. 5, the $Y$ chromosome is included in the analysis and it is seen that the $\mathrm{Y}$ chromosome is morphologically similar to the chromosomes in the G group. The D group is also a "near neighbor" 
in the plot and it is seen that 33 of the chromosomes allocated to the $\mathrm{D}$ group by the cytologist were classified as a $\mathrm{Y}$ chromosome by the discriminant function analysis.

We turn now to the question of whether or not the measurements considered in this study can be used to identify individual chromosomes. This can be investigated by considering each of the 24 chromosomes as a group in the discriminant function analysis and the classification matrix for this situation is given in Table 8. For convenience of reference, the chromosomes are identified individually by number ( $\mathrm{X}$ is No. $23, \mathrm{Y}$ is No. 24) but the boxes in the matrix show group membership. Thus the diagonal entries are correct identifications; the off-diagonal entries inside the boxes represent incorrect identifications, but a correct group classification; the entries outside of the boxes representing an error both of identification and of group membership. Again, the most serious confusion is between the $\mathrm{X}$ chromosome and chromosomes in the $\mathrm{C}$ group (specifically No.6, No.7 and No.8) and the Y chromosome and the chromosomes in the G group.

\section{Discussion}

The results summarized above indicate that while chromosomes can be grouped with a reasonably high probability of success using measurements alone (6.5\% of the autosomes were misclassified) identification of individual chromosomes is somewhat more difficult (Table 8). Within certain of the autosomal groups relatively accurate identification of individual members is possible, as in the A group (cf. Moore and Gregory, 1963), the B group and the $D$ group, but the other groups present more serious problems not only with respect to the identification of individual chromosomes but also with respect to the accurate determination of group membership. This is especially true when the sex chromosomes are included in the analysis. Identification of the sex chromosomes poses a special problem. There is justified skepticism concerning the recognition of the $\mathrm{X}$ among the similar submetacentrics in Group C. The variability of the somewhat allocyclic $X$ in relation to the autosomes handicaps any effort to pinpoint the $X$ in a karyogram by means of a statistical analysis, as was noted earlier by Patau (1960). Penrose (1964) went so far as to say that, "... discrimination between the $\mathrm{X}$ and No. 6 by metrical methods is not possible". But one need not conclude that the position of the $\mathrm{X}$ chromosome within the $\mathrm{C}$ group remains entirely conjectural; nor that measurement cannot aid in its identification. While our data do support the notion that the $\mathrm{X}$ and No. 6 chromosomes are morphologically similar, we do suggest that the probability of a correct identification can be enhanced by measurements made on these chromosomes. 
Table 8. Classification matrix for the discriminant analysis using all available

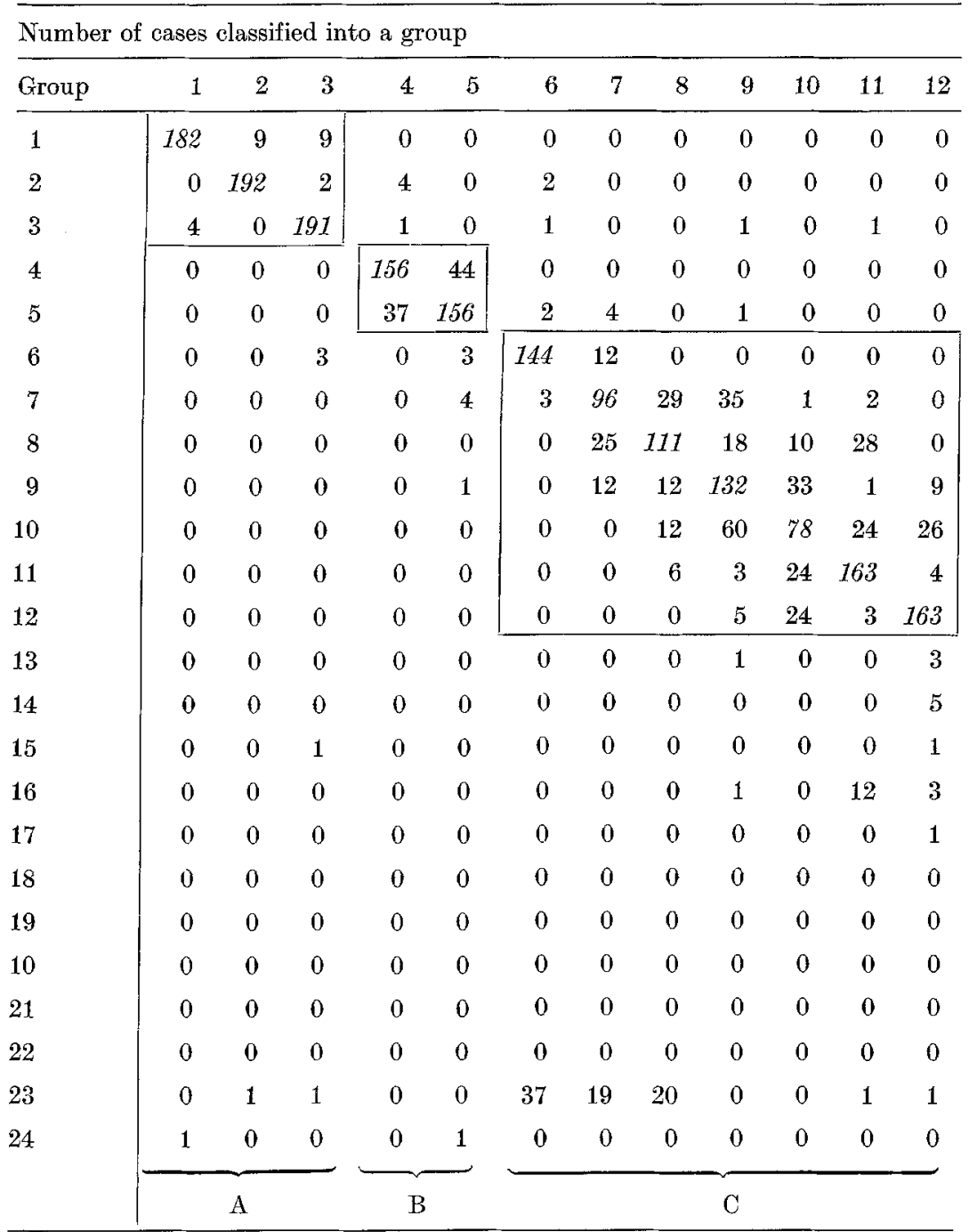

Number of cases classified into a group

Other means (e.g., Sharat Chandra and Hungerford, 1967) for distinguishing between these chromosomes can, of course, be used in conjunction with the probabilities computed using the measurements to arrive at the final decision. Similar remarks hold for the identification of the $\mathrm{Y}$ chromosome, though it is generally recognized that the $\mathrm{Y}$ is 
measurements and considering each chromosome as a group

\begin{tabular}{|c|c|c|c|c|c|c|c|c|c|c|c|}
\hline 13 & 14 & 15 & 16 & 17 & 18 & 19 & 20 & 21 & 22 & 23 & 24 \\
\hline 0 & 0 & 0 & 0 & 0 & 0 & 0 & 0 & 0 & 0 & 0 & 0 \\
\hline 0 & 0 & 0 & 0 & 0 & 0 & 0 & 0 & 0 & 0 & 0 & 0 \\
\hline 0 & 0 & 0 & 0 & 0 & 0 & 0 & 0 & 0 & 0 & 1 & 0 \\
\hline 0 & 0 & 0 & 0 & 0 & 0 & 0 & 0 & 0 & 0 & 0 & 0 \\
\hline 0 & 0 & 0 & 0 & 0 & 0 & 0 & 0 & 0 & 0 & 0 & 0 \\
\hline 1 & 0 & 0 & 0 & 0 & 0 & 0 & 0 & 0 & 0 & 37 & 0 \\
\hline 0 & 0 & 0 & 0 & 0 & 0 & 0 & 0 & 0 & 0 & 30 & 0 \\
\hline 0 & 0 & 0 & 0 & 0 & 0 & 0 & 0 & 0 & 0 & 8 & 0 \\
\hline 0 & 0 & 0 & 0 & 0 & 0 & 0 & 0 & 0 & 0 & 0 & 0 \\
\hline 0 & 0 & 0 & 0 & 0 & 0 & 0 & 0 & 0 & 0 & 0 & 0 \\
\hline 0 & 0 & 0 & 0 & 0 & 0 & 0 & 0 & 0 & 0 & 0 & 0 \\
\hline 1 & 0 & 0 & 3 & 1 & 0 & 0 & 0 & 0 & 0 & 0 & 0 \\
\hline 133 & 47 & 16 & 0 & 0 & 0 & 0 & 0 & 0 & 0 & 0 & 0 \\
\hline 44 & 110 & 39 & 0 & 0 & 2 & 0 & 0 & 0 & 0 & 0 & 0 \\
\hline 7 & 42 & 140 & 1 & 0 & 5 & 0 & 0 & 0 & 0 & 0 & 3 \\
\hline 0 & 0 & 0 & 163 & 13 & 0 & 8 & 0 & 0 & 0 & 0 & 0 \\
\hline 0 & 0 & 0 & 14 & 147 & 38 & 0 & 0 & 0 & 0 & 0 & 0 \\
\hline 0 & 0 & 1 & 0 & 33 & 154 & 1 & 2 & 3 & 0 & 0 & 6 \\
\hline 0 & 0 & 0 & 16 & 1 & 0 & 115 & 68 & 0 & 0 & 0 & 0 \\
\hline 0 & 0 & 0 & 0 & 2 & 3 & 51 & 144 & 0 & 0 & 0 & 0 \\
\hline 0 & 0 & 1 & 0 & 1 & 27 & 0 & 2 & 93 & 33 & 0 & 43 \\
\hline 0 & 0 & 1 & 0 & 0 & 2 & 0 & 2 & 62 & 96 & 1 & 36 \\
\hline 0 & 0 & 0 & 0 & 0 & 1 & 0 & 0 & 0 & 0 & 119 & 0 \\
\hline 0 & 0 & 5 & 0 & 0 & 1 & 0 & 0 & 20 & 12 & 0 & 59 \\
\hline \multicolumn{3}{|c|}{$\mathrm{D}$} & \multicolumn{3}{|c|}{$\mathrm{E}$} & \multicolumn{2}{|c|}{$\mathrm{F}$} & \multicolumn{2}{|l|}{$G$} & $\mathrm{x}$ & $\mathrm{Y}$ \\
\hline
\end{tabular}

more easily identified than the $X$. As regards using measurements alone to make this identification, we may note that in calculating arm ratios for the tiny acrocentric $\mathrm{Y}$, which is generally just slightly larger than the two smallest autosomes (No.21 and No.22), considerable overlap in the distributions of these measurements is to be expected and other 
means (e.g. Miller et al., 1963) may have to be incorporated if the probability of a correct identification is to attain an acceptably high magnitude.

We also studied the chromosomes which were misclassified by the discriminant function analysis in an attempt to discover why these chromosomes could not be distinguished by morphological means. In virtually every case we found that the misclassified chromosome had contracted to a different degree than had those which were correctly classified. It should be noted that the discriminant function analysis operates on the distances between the mean values of the measurements in the various groups and that these mean values must be considered not only as averages for the particular population of cells, which are measured, but also as averages for the stages of mitosis selected for convenience (Penrose, 1964). The difficulty is that colchicine causes contraction of the chromosomes to an extent that depends upon the time during which the drug has been present and its concentration. Apparently, the degree of contraction of all the chromosomes is not constant. Thus the relative sizes of the chromosomes may be altered according to the stage of metaphase in the cell which is selected for study. As pointed out by Penrose (1964), the largest chromosomes may contract more in later stages than the smaller ones. Consequently, it should be recognized that a number of the misclassifications might be attributed to a failure in ensuring that all the chromosomes are equally condensed or stretched during the preparation of the karyotype as opposed to an inherent limitation of the discrimination procedure per se. In any event, the degree of contraction of the individual chromosomes has been found to be an important factor in the classification of chromosomes and it is suggested that attempts should be made to control this factor both at the technical (in selecting the cells to be studied) and analytical (perhaps by using a correction factor) levels.

The results of this study indicate the extent to which identification of individual chromosomes and groups of chromosomes can be made on the basis of (certain) measurements alone. The results are, therefore, relevant to questions concerning the feasibility of developing automated chromosomal analyses based on morphological data. As noted in the Chicago Conference (1966), "Chromosome analysis is a sequence of operations, and automation should be applicable to many if not all stages, from the collection of blood to the printing of a report... In addition to reliability and economy, machine analysis offers the promise of an extension of perception beyond present limits." Jacobs (1965) has given a concise exposition of the need for automation and Ledley and Ruddle (1965) have described one approach to the solution of the problem. But, no matter which automated approach is adopted, it must 
be recognized that the computer will be programmed to recognize and classify chromosomes by doing many of the same things the investigator would and the present study describes the accuracy which might be expected using certain chromosomal measurements as discriminators. Incorporation of other information, including additional metrical characteristics, can only increase the precision with which the chromosomes are identified. Thus there is reason to hope that automated analyses will eventually be perfected to the extent that they uncover small but important chromosomal aberrations that have not been discerned by eye. It is known, e.g., that one of the chromosomes in the cells of individuals with chronic myeloid leukemia lacks only a small portion of one arm (Jacobs, 1965) and it seems likely that other small deletions or additions have been overlooked by cytologists which may be revealed by the application of automated morphological analyses representing quantitative rather than only qualitative variation.

In closing, we might point out that recent advances in the identification of human chromosomes by DNA-binding fluorescent agents (see, e.g. Caspersson et al., 1970, 1971) have provided another approach to identification of metaphase chromosomes. In our opinion, DNAbinding should not be viewed as a competitor of metrical methods. Rather, consideration should be given to using these methods in conjunction with one another in order to achieve the most accurate means for chromosome identification.

\section{References}

Anderson, T. W.: An introduction to multivariate statistical analysis. New York: Wiley 1958.

Blackith, R. E., Reyment, R. A. : Multivariate morphometrics. New York: Academic Press 1971.

Caspersson, T., Lomakka, G., Lorezech, G.: The 24 fluorescense patterns of the human metaphase chromosomes-distinguishing characters and variability. Hereditas (Lund) 67, 89-102 (1971).

Caspersson, T., Zech, L., Johansson, C., Modest, E. J.: Identification of human chromosomes by DNA-binding fluorescent agents. Chromosoma (Berl.) 30, 215-227 (1970).

Chicago Conference: Standardization in human cytogenetics. Birth defects : Original Article Series II, 2. New York: The National Foundation 1966.

Chu, E. H., Giles, N. H.: Human chromosome complements in normal somatic cells in culture. Amer. J. hum. Genet. 11, 63-79 (1959).

Denver Conference. A proposed standard system of nomenclature of human mitotic chromosomes. Lancet 1960I, 1063-1065.

Dixon, W.J. (ed.): Biomedical computer programs. Berkeley: University of California Press 1967.

Fisher, R.A.: The use of multiple measurements in taxonomic problems. Ann. Eugen. (Lond.) 7, 179-188 (1936).

Ford, C. E.: Methods in human cytogenetics. In: Methodology in human genetics (W. J. Burdette, ed.). San Francisco: Holden-Day 1962. 
Healey, J. J. R.: Descriptive uses of discriminant functions. In: Mathematics and computer seience in biology and medieine. London: H. M. S. O. 1965.

Hodges, J. L.: Discriminatory analysis: 1. Survey of discriminatory analysis. Report No. 1, USAF School of Aviation Medicine, Randolph Field, Texas, 1950.

Jacobs, P. A.: Counting and analysis of human chromosomes. In: Mathematics and computer science in biology and medicine. London: H.M.S.O. 1965.

Kowalski, C. J.: A commentary on the use of multivariate statistical methods in anthropometric research. Amer. J. Phys. Anthrop. 36, 119-131 (1972).

Lanchenbruch, P.A.: Discriminant analysis when the initial samples are misclassified. Technometries 8, 657-662 (1966).

Ledley, R. S., Ruddle, F. H.: Automatic analysis of chromosome karyograms. In: Mathematics and computer science in biology and medicine. London: H.M.S.O. 1965.

Miller, O. J., Mukherjee, B. B., Breg, W. R., Gamble, A. van: Non-random distribution of chromosomes in metaphase figures from cultured human leucocytes. I. The peripheral location of the $\mathrm{Y}$ chromosome. Cytogenetics 2, 1-14 (1963).

Moore, R. C., Gregory, G.: Biometrics of the karyotype of protemnodon bicolor, with reference to the limitations in accuracy of identifying human chromosomes. Nature (Lond.) 200, 234-237 (1963).

Moorehead, P. S., Nowell, P. C., Mellman, W. J., Batipps, D. D., Hungerford, D. M. : Chromosome preparations of leucocytes cultured from human peripheral blood. Exp. Cell Res. 20, 613-616 (1960).

Nasjleti, C. E., Walden, J. M., Spencer, H. H.: Polypoidization and aberration of human chromosomes induced in vitro and in vivo with ionizing radiations. J. nucl. Med. 7, 159-176 (1966).

Patau, K. The identification of individual chromosomes, especially in man. Amer. J. hum. Genet. 12, 250-276 (1960).

Patau, K.: Discussion of methods in human eytogeneties by C. E. Ford. In: Methodology in human genetics (W. J. Burdette, ed.). San Francisco: HoldenDay 1962.

Penrose, L. S.: A note on the mean measurements of human chromosomes. Ann. hum. Genet. 28, 195-196 (1964).

Radhakrishna, S.: Discrimination analysis in medicine. Statistician 14, 147-163 (1964).

Seabright, M.: A rapid banding technique for human chromosomes. Lancet 1971 II, $971-972$.

Sharat Chandra, H., Hungerford, D. A.: Identification of the human X chromosome: A Reconciliation between results obtained from morphological and from radioautographic studies. Ann. Génét. 10, 13-17 (1967).

Tatsuoka, M. M., Tiedeman, D. V.: Discriminant analysis. Rev. Educ. Res. 24, $402-420$ (1954).

Tjio, J. H., Puck, T. T.: The somatic chromosome of man. Proc. nat. Acad. Sci. (Wash.) 44, 1229-1237 (1958).

Received July 26, 1972 / Accepted by R. B. Nicklas

Ready for press September 5, 1972

Dr. Charles J. Kowalski

Statistical Research Laboratory

106 Rackham Building

University of Michigan

Ann Arbor, Michigan 48104

U.S.A. 